\title{
Brief Behavioural Activation (Brief BA) for adolescent depression: a pilot study
}

Article

Accepted Version

Pass, L., Lejuez, C. W. and Reynolds, S. (2018) Brief

Behavioural Activation (Brief BA) for adolescent depression: a pilot study. Behavioural and Cognitive Psychotherapy, 46 (2). pp. 182-194. ISSN 1352-4658 doi:

https://doi.org/10.1017/S1352465817000443 Available at https://centaur.reading.ac.uk/71972/

It is advisable to refer to the publisher's version if you intend to cite from the work. See Guidance on citing.

Published version at: https://www.cambridge.org/core/journals/behavioural-and-cognitive-psychotherapy/article/briefbehavioural-activation-brief-ba-for-adolescent-depression-a-pilot-study/0D58F49E444B3B2FB8CFB2223FCDC2B1

To link to this article DOI: http://dx.doi.org/10.1017/S1352465817000443

Publisher: Cambridge University Press

Publisher statement: This article has been accepted for publication (First View) in Behavioural and Cognitive Psychotherapy by Cambridge University Press, and should be referenced as: Pass, L., Lejuez, C. W., \& Reynolds, S. (2017). Brief Behavioural Activation (Brief BA) for Adolescent Depression: A Pilot Study. Behavioural and Cognitive Psychotherapy, 1-13.

doi:10.1017/S1352465817000443 The published article can be accessed here: https://www.cambridge.org/core/journals/behavioural-and-cognitive-psychotherapy The British Association for Behavioural and Cognitive Psychotherapies owns full copyright in all forms and media for this publication.

All outputs in CentAUR are protected by Intellectual Property Rights law, including copyright law. Copyright and IPR is retained by the creators or other copyright holders. Terms and conditions for use of this material are defined in 
the End User Agreement.

www.reading.ac.uk/centaur

\section{CentAUR}

Central Archive at the University of Reading

Reading's research outputs online 


\title{
Brief Behavioural Activation (Brief BA) for adolescent depression: A pilot study
}

Note: This article has been accepted for publication (First View) in Behavioural and Cognitive Psychotherapy by Cambridge University Press, and should be referenced as:

Pass, L., Lejuez, C. W., \& Reynolds, S. (2017). Brief Behavioural Activation (Brief BA) for Adolescent Depression: A Pilot Study. Behavioural and Cognitive Psychotherapy, 1-13. doi:10.1017/S1352465817000443

The published article can be accessed here: https://www.cambridge.org/core/journals/behavioural-and-cognitive-psychotherapy The British Association for Behavioural and Cognitive Psychotherapies owns full copyright in all forms and media for this publication.

\begin{abstract}
Background: Depression in adolescence is a common and serious mental health problem. In the UK, access to evidence based psychological treatments is limited and training and employing therapists to deliver these is expensive. Brief Behavioral Activation for the Treatment of Depression (BATD) has great potential for use with adolescents and to be delivered by a range of healthcare professionals, but there is limited empirical investigation with this group.
\end{abstract}

Aims: To adapt BATD for depressed adolescents (Brief BA) and conduct a pilot study to assess feasibility, acceptability and clinical effectiveness.

Methods: Twenty depressed adolescents referred to the local NHS Child and Adolescent Mental Health service (CAMHs) were offered 8 sessions of Brief BA followed by a review around one month later. Self- and parent- reported Routine Outcome Measures (ROMs) were collected at every session.

Results: Nineteen of the 20 young people fully engaged with the treatment and all reported finding some aspect of Brief BA helpful. Thirteen (65\%) required no further psychological intervention following Brief BA, and both young people and parents reported high levels of acceptability and satisfaction with the approach. The pre-post effect size of Brief BA treatment was large.

Conclusions: Brief BA is a promising innovation in the treatment of adolescent depression. This approach requires further evaluation to establish effectiveness and cost effectiveness 
compared with existing evidence-based treatments for adolescent depression. Other questions concern the effectiveness of delivery in other settings and when delivered by a range of professionals.

\section{Adolescent Depression}

Depression is a serious mental health problem in adolescence, with $2.6 \%$ of the world youth population experiencing depression at any one time (Polanczyk, Salum, Sugaya, Caye and Rohde, 2015). Core symptoms include depressed mood or irritability, and/or a loss of interest and pleasure (anhedonia) along with other cognitive and behavioural changes including appetite and sleep disturbances, cognitive difficulties and negative self-perceptions (American Psychological Association, 1994). Depression in adolescence predicts a wide range of long-term negative impacts, including mental illness in adulthood (McLeod, Horwood and Fergusson, 2016), educational underachievement (Fletcher, 2008), and increased risk of suicidal behaviour (Cash and Bridge, 2009).

\section{Adolescent Depression Treatments}

The current National Institute for Health and Care Excellence (NICE) guidelines for treatment of moderate/severe depression in young people recommend individual CognitiveBehavioural Therapy (CBT), Interpersonal Therapy (IPT), family therapy or psychodynamic psychotherapy for at least three months (NICE, 2015). NICE recommend that such therapies should only be provided by healthcare professionals trained to an appropriate standard of competence. However, there are a limited number of therapists with these qualifications which can be a barrier to accessing these treatments. Waiting times in CAMH services across the UK are extremely variable (National Society for the Prevention of Cruelty to Children, 2015), can be lengthy (House of Commons Health Committee, 2014) and GPs report inadequate CAMH provision for the young people they try to refer (Stem4, 2016). Evidencebased treatments are simply not able to meet the needs of the majority of depressed young people

There are also difficulties engaging depressed adolescents in psychological therapy. Recent trials have evidenced a significant level of drop out from CBT and other therapies (Goodyer et al., 2016), and a meta-analysis of adolescent depression treatments found psychological interventions with a cognitive component were no more effective than those without cognitive work (Weisz, McCarty and Valeri, 2006). 


\section{Behavioural Activation for Depression}

In the UK Behavioural Activation (BA) is recommended as an evidence-based treatment for adult depression (NICE, 2016). BA is based on the behavioural theory of depression and aims to improve mood by increasing positive reinforcement for healthy behaviours. Meta-analyses suggest that BA is equivalent to CBT for adults with depression (Cuijpers, van Straten, Andersson and van Oppen, 2008; Ekers, Richards and Gilbody, 2008) and can be more effective than medication (Ekers et al., 2014). Two contemporary BA approaches have been developed. One involves 16-20 sessions (BA; Martell, Addis and Jacobson, 2001; Martell, Dimidjian and Hermann-Dunn, 2010) and the other is a brief, more structured approach (Behavioral Activation Treatment for Depression, BATD: Lejuez, Hopko and Hopko, 2001; Lejuez, Hopko, Acierno, Daughters and Pagoto, 2011).

Treatment complexity/length and clinician level of training do not affect BA treatment outcome (Ekers et al., 2008). Because BA can be delivered by staff who are not formally trained as psychological therapists, it is more cost effective than CBT (Richards et al., 2016).

\section{Brief BA for Adolescent Depression}

Almost no work has applied BA to adolescents, despite many aspects of BA fitting well with the characteristics of this developmental period (e.g. lower cognitive demands, ability to individualise therapy within a straightforward approach). Ruggiero, Morris, Hopko and Lejuez (2005) reported a case study of using BATD successfully with a depressed adolescent, with an indication that depression symptoms reduced as reinforcing life events increased. One small RCT $(N=60)$ has evaluated Martell-based, 14 session BA with depressed adolescents in the USA (McCauley et al., 2015). Adolescents were randomised to either BA or evidence-based practice for depression, and both groups showed significant improvements in depression symptoms and functioning (with no difference between groups).

To create a more streamlined BA intervention, Pass and Reynolds (2014) adapted BATD for use in routine CAMHs settings in the UK (see Pass, Brisco and Reynolds, 2015). The aim was to create a brief, structured behavioural intervention that was acceptable to young people and could be delivered by a range of professionals, in order to increase treatment accessibility. Treatment takes 6-8 sessions, involves parents and is delivered using a structured session by session workbook (Pass \& Reynolds, 2014) and therapist guide (Pass, Brisco, Hodgson, \& Reynolds,2015). It can be used in cases where there is self-harm/suicidal ideation (Pass, Whitney and Reynolds, 2016) and can be delivered successfully by non- 
specialist clinicians (Pass, Hodgson, Whitney and Reynolds, in press). This study reports the outcomes from a pilot and feasibility study of Brief BA in NHS CAMHs with data from 20 consecutive cases referred for treatment.

\section{Method}

\section{Procedure}

The study was completed within a local CAMHs Anxiety and Depression pathway. Potential participants were identified by NHS clinicians if they wished to receive treatment for depression. Brief BA was offered when a BA therapist and supervision was available. Clinicians outlined the usual treatment options (typically CBT, sometimes with SSRI medication if indicated) and described Brief BA to young people and parents. Collaborative decision-making determined treatment choice.

[Local NHS Trust name removed for blind review] NHS Foundation Trust provided approval for an audit of these cases and dissemination of the findings (ref: 2623). All data obtained from young people and parents were part of service routine data collection.

\section{Participants}

Participants were the first 20 young people who opted to receive Brief BA treatment, referred between February 2014 and August 2015. Strict inclusion/exclusion criteria were not used; referrals were received from clinicians within the service for young people with depressive symptoms causing significant impairment in functioning. Therefore this case series was uncontrolled and unblinded, with no comparison group.

\section{Measures}

\section{Revised Child Anxiety and Depression Scale: Child and Parent versions} (RCADS, RCADS-P; Chorpita, Yim, Moffitt, Umemoto and Francis, 2000). The RCADS and RCADS-P are 47-item questionnaires assessing anxiety and low mood in 8-18 year olds. Both have good psychometric properties (e.g. Chorpita et al., 2000; Chorpita, Moffitt and Gray, 2005; Ebesutani, Bernstein, Nakamura, Chorpita and Weisz, 2010), and provide age and gender normed t-scores with clinical cut offs (t scores of 0-64= normal range, 65-69= borderline clinical range, 70+= clinical range). The full RCADS and RCADS$\mathrm{P}$ were completed at assessment and final treatment session. The self and parent report Depression subscales were completed at the start of every BA session and was the primary 
outcome measure. An additional question ('I thought about killing myself'/'My child thought about killing themselves') was added to monitor risk.

Outcome Rating Scale (ORS; Miller and Duncan, 2000). The ORS is a measure of functioning in four areas: Individual, Interpersonal, Social and Overall. These are marked on four $10 \mathrm{~cm}$ visual analog scales which are summed to give a total score, with higher scores indicating higher functioning. Young people and their parent were asked to rate the ORS every session. The ORS has good concurrent validity with other treatment outcome measures and high internal consistency and test retest reliability (Duncan, Sparks, Miller, Bohanske and Claud, 2006).

Session Rating Scale (SRS; Duncan et al., 2003). The SRS is an ultra-brief measure of therapeutic alliance. Similar to the ORS, the SRS scores are marked on four $10 \mathrm{~cm}$ visual analog scales which are summed to give a total score across four areas: Relationship, Goals and Topics, Approach or Method, and Overall Alliance. A higher score indicates a higher client rating of therapeutic alliance. The SRS has good psychometrics, including moderate concurrent validity with longer self-report measures of alliance (Duncan et al., 2003). The SRS was completed after each session by the young person.

Brief BA feedback questionnaire. At the end of treatment young people and parents were asked to complete a questionnaire about their experiences of Brief BA. There were three forced choice questions about whether they liked the approach ('really liked it to "hated it'), whether they found BA useful ('very' to 'not at all'), and whether they would recommend BA to a friend/for a friend's child ('yes definitely' to 'definitely not'). Young people and parents were also asked open ended questions about what they liked best about BA, what they liked least, and any other comments including about the practical resources.

\section{Participant Characteristics}

Most participants were white, 16 year old females, representative of all young people who were referred with depression during this period (Orchard et al., 2016). Ten had at least one comorbid anxiety disorder (see Table 1), and in addition one had a diagnosis of Chronic Fatigue Syndrome (CFS) and another was waiting for an Autism Spectrum Disorder (ASD) assessment. There were no comorbid behavioural diagnoses. 
Nine young people were taking prescribed SSRI medication, and two of these had changes in medication type/dose during Brief BA treatment following Psychiatry reviews. Thirteen young people reported active suicidal ideation assessment, indicating an active plan to end their life.

Four participants had previously received CBT (two for anxiety and two for depression). A higher proportion had accessed some form of counselling, but this varied greatly and clinical records were not available to accurately assess this.

Table 1: Participant characteristics

\begin{tabular}{ll}
\hline Characteristic & Total $(\%)$ \\
\hline Gender (\% female) & $18(90 \%)$ \\
Mean age in years (SD) & $16.12(0.71)$ \\
Age range (years) & $14-17$ \\
Ethnicity & $18(90 \%)$ \\
$\quad-\quad$ Caucasian & $2(10 \%)$ \\
$\quad-$ Other &
\end{tabular}

Active suicidal ideation

$13(65 \%)$

Anti-depressant medication

$9(45 \%)$

Previous psychological therapy

$4(20 \%)$

Comorbidity

- None

$10(50 \%)$

- One anxiety disorder

- Two anxiety disorders

$2(10 \%)$

$-3+$ anxiety disorders

$1(5 \%)$

Family involvement in Brief BA

- None $1(5 \%)$

- Minimal $1(5 \%)$

- Routine $18(90 \%)$ 


\section{Brief BA Treatment}

Brief BA involves 6-8 one-hour individual sessions with structured parental involvement in part of sessions 1,6 and 8. There is a review session with young person and parent approximately one month after the final treatment session (see Table 2 for Brief BA overview). One young person did not have any parental involvement as she was attending boarding school, and another attended most sessions alone and parental involvement was minimal.

Table 2: Brief BA for adolescent depression: Session overview

\begin{tabular}{|c|c|c|c|}
\hline Session & Young person content & Parent content & Homework \\
\hline 1 & $\begin{array}{l}\text { Introduction to Brief BA approach } \\
\text { and rationale, session workbook. }\end{array}$ & $\begin{array}{l}\text { Attend part of session } \\
\text { (rationale, structure of Brief } \\
\text { BA), parent workbook. }\end{array}$ & $\begin{array}{l}\text { Activity } \\
\log \end{array}$ \\
\hline 2 & $\begin{array}{l}\text { Review of Brief BA approach, } \\
\text { review of activity log, session } \\
\text { workbook. }\end{array}$ & Parent workbook & $\begin{array}{l}\text { Activity } \\
\log \end{array}$ \\
\hline 3 & $\begin{array}{l}\text { Review of activity log, introduction } \\
\text { to values, session workbook. }\end{array}$ & Parent workbook & $\begin{array}{l}\text { Activity } \\
\log , \text { Values }\end{array}$ \\
\hline $4-5$ & $\begin{array}{l}\text { Review of values, plan valued } \\
\text { activities across life areas, session } \\
\text { workbook. }\end{array}$ & Parent workbook & $\begin{array}{l}\text { Valued } \\
\text { activities }\end{array}$ \\
\hline 6 & $\begin{array}{l}\text { Review of progress, introduction to } \\
\text { problem-solving and contracting, } \\
\text { session workbook. }\end{array}$ & $\begin{array}{l}\text { Attend part of session } \\
\text { (review, problem-solving, } \\
\text { contracts), parent workbook. }\end{array}$ & $\begin{array}{l}\text { Valued } \\
\text { activities }\end{array}$ \\
\hline 7 & $\begin{array}{l}\text { Review of progress, identification } \\
\text { of activities to continue working } \\
\text { towards, session workbook. }\end{array}$ & Parent workbook & $\begin{array}{l}\text { Valued } \\
\text { activities }\end{array}$ \\
\hline 8 & $\begin{array}{l}\text { Review of progress, relapse } \\
\text { prevention, session workbook, } \\
\text { relapse prevention handout. }\end{array}$ & $\begin{array}{l}\text { Attend part of session } \\
\text { (review, relapse prevention), } \\
\text { parent workbook. }\end{array}$ & \\
\hline Review & $\begin{array}{l}\text { Review of progress, plan for further } \\
\text { input/discharge. }\end{array}$ & Attend part of review & \\
\hline
\end{tabular}




\section{Brief BA Clinicians and Supervision}

Brief BA was delivered in the routine CAMHs setting by three therapists including a clinical psychologist $(n=12)$ and two graduate psychologists, both of whom received additional training in Brief BA (4 cases each). For further details on Brief BA training for clinicians, see Pass et al. (under review). Supervision was provided by a clinical psychologist involved in the adaptations for Brief BA. During Brief BA other multidisciplinary clinical care was provided as appropriate (e.g. ongoing Psychiatry reviews).

\section{Treatment Adherence}

No treatment adherence measure is available for Brief BA. However, all clinicians sought consent for audio recording of sessions, and a random selection of tapes were listened to by one of the developers of Brief BA (LP). BA supervision was held fortnightly (weekly for the first training case for each clinician) and used treatment audio recordings.

\section{Analysis plan}

Data were explored to assess the assumptions of parametric testing (paired t-tests). Where variables violated these assumptions, a non-parametric equivalent test was used (Wilcoxon signed ranks test) and any change to the results reported, for all analyses a $p<.05$ significance level was used. We used an 'Intent to treat' (ITT) analysis; all participants were included in the analysis. Where data were missing, a last observation carried forward (LOCF) procedure was used. The exception to this was when no data was available at any time point. For data missing from assessment, a first observation carried backwards (FOCB) procedure was used.

\section{Results}

\section{Engagement}

Out of the 20 adolescents who started Brief BA, 19 engaged with the treatment and 18 completed all eight sessions and review. One young person reported that Brief BA was not the right treatment for her after four sessions. Two more sessions were used to review her symptoms and progress, before discontinuing Brief BA and putting her onto the waiting list for CBT. She subsequently declined CBT or any other input and was discharged from the service. Another young person attended four sessions of Brief BA then was discharged because her symptoms remitted. 


\section{Primary Outcome: RCADS Depression Subscale}

Pre- and post-treatment data for the RCADS Depression subscale are presented in

Table 3. The data were slightly non-normally distributed, so pre/post comparisons were run both with parametric and non-parametric tests. There was no difference in results, so parametric tests are reported for simplicity along with bias corrected and accelerated (BCa) bootstrapped $95 \%$ confidence intervals.

Table 3: Pre- and post- Brief BA RCADS Depression subscale raw scores

\begin{tabular}{lcllll}
\hline $\begin{array}{l}\text { Respondent and time } \\
\text { point }\end{array}$ & $\mathrm{N}$ & $\begin{array}{l}\text { Mean raw } \\
\text { score (SD) }\end{array}$ & $\begin{array}{l}\text { Raw score } \\
\text { range }\end{array}$ & $\begin{array}{l}\text { Median } \\
\text { raw score }\end{array}$ & $\begin{array}{l}\text { Interquartile } \\
\text { range }\end{array}$ \\
\hline $\begin{array}{l}\text { Self-report RCADS-Dep } \\
\text { Baseline assessment }\end{array}$ & 20 & $20.65(5.66)$ & $8-28$ & 21 & $17-25.75$ \\
Session 8 & 20 & $15.00(6.79)$ & $5-30$ & 14 & $9.5-19.5$ \\
Review & 20 & $14.45(7.98)$ & $2-30$ & 12.5 & $8.75-20.75$ \\
\hline Parent-report RCADS-Dep & & & & \\
\hline Baseline assessment & 19 & $16.58(5.85)$ & $8-29$ & 16 & $12-22$ \\
Session 8 & 19 & $11.63(3.95)$ & $5-21$ & 11 & $8-14$ \\
Review & 19 & $10.66(6.52)$ & $1-29$ & 10 & $6-14$ \\
\hline
\end{tabular}

As shown in Table 4, there was a significant reduction in self-reported depression symptoms from assessment to session 8 , and from assessment to review. This reduction was also shown by mean t-scores moving from the clinical range at assessment $(M=82.25, S D=$ $15.95)$, to the borderline range at session $8(M=66.25, S D=16.19)$ and review $(M=65.40$, $S D=19.91)$. This decrease equates to a large effect size $(0.2=$ small, $0.5=$ medium, 0.8 or above $=$ large effect size; Cohen, 1992).

Table 4: Pre and post comparisons of RCADS-Depression raw scores

\begin{tabular}{llllll}
\hline $\begin{array}{l}\text { Respondent and comparison } \\
\text { time points }\end{array}$ & $\mathrm{N}$ & $\mathrm{df}$ & T-value & $\begin{array}{l}\text { BCa bootstrapped } \\
95 \% \mathrm{CI}\end{array}$ & Cohen's $d$ \\
\hline $\begin{array}{l}\text { Self-report RCADS-Dep } \\
\text { Assessment }- \text { Session } 8\end{array}$ & 20 & 19 & $3.97 * *$ & {$[2.50-8.83]$} & 0.90 \\
Assessment - Review & 20 & 19 & $4.30^{* *}$ & {$[3.20-9.55]$} & 0.90 \\
\hline
\end{tabular}

Parent report RCADS-Dep 


\begin{tabular}{llllll} 
Assessment - Session 8 & 19 & 18 & $5.50 * *$ & {$[3.26-6.68]$} & 0.99 \\
Assessment - Review & 19 & 18 & $4.10^{* *}$ & {$[3.27-8.90]$} & 0.96 \\
\hline \multicolumn{7}{c}{$*=<.05, * *=p<.01$}
\end{tabular}

\section{Parent-report RCADS Depression Subscale}

The pre- and post-treatment mean scores for the parent-reported RCADS Depression subscale are shown in Table 3, and the pre and post comparisons in Table 4. There was a significant reduction in parent-reported RCADS Depression scores from assessment to session 8 , and from assessment to review. The parental mean t-scores reduced but stayed in the clinical range across time points (assessment $M=86.53, S D=18.21$; session $8 M=$ $72.00, S D=11.92$; review $M=69.24, S D=19.59$ ). In line with self-report scores, the parentreported reduction in depression symptoms equates to a large effect size (Cohen, 1992).

\section{Secondary Analyses: Outcome Rating Scale}

The ORS was completed for the first time at the beginning of session 1 as it was not part of the assessment measures. The pre- and post-treatment mean ORS scores are presented in Table 5. There was a significant increase in self-reported functioning from session 1 to session $8(t(17)=-2.51, p=.022, d=0.73)$, and from session 1 to review $(t(17)=-2.44, p=$ $.026, d=0.73)$. Parental report also indicated a significant increase in functioning from session 1 to session $8(t(15)=-5.60, p<.001, d=1.47)$ and from session 1 to review $(t(15)=$ $-4.69, p<.001, d=1.12$ ). The treatment effect size was medium for self-report, and large for parent-report (Cohen, 1992).

Table 5: Pre and Post-Brief BA ORS scores

\begin{tabular}{lcllll}
\hline $\begin{array}{l}\text { Respondent and } \\
\text { time point }\end{array}$ & $\mathrm{N}$ & $\begin{array}{l}\text { Mean score } \\
(\mathrm{SD})\end{array}$ & Range & Median & $\begin{array}{l}\text { Interquartile } \\
\text { range }\end{array}$ \\
\hline $\begin{array}{l}\text { Self-report ORS } \\
\text { Session 1 }\end{array}$ & 18 & $18.21(9.33)$ & $1.10-36.95$ & 16.05 & $12.88-25.10$ \\
Session 8 & 18 & $25.30(10.16)$ & $8.00-38.30$ & 27.45 & $17.63-33.38$ \\
Review & 18 & $25.69(11.23)$ & $4.90-39.10$ & 29.55 & $15.83-35.31$ \\
\hline $\begin{array}{l}\text { Parent report ORS } \\
\text { Session 1 }\end{array}$ & 16 & $17.73(8.67)$ & $4.40-31.20$ & 18.55 & $11.85-26.33$
\end{tabular}




$\begin{array}{llllll}\text { Session } 8 & 16 & 30.04(8.11) & 8.80-38.50 & 32.60 & 25.38-35.65 \\ \text { Review } & 16 & 28.21(10.06) & 3.10-39.90 & 28.05 & 21.03-36.88\end{array}$

Note: Case 7 excluded as she did not feel her ORS self-report was valid, so this measure was discontinued; Case 17 excluded as both self and parent-report ORS score were 0 at session 1, indicating a lack of validity; Case 9 had no parent ORS data; Case 15 excluded as parent ORS only available from session 6.

\section{Clinical outcomes}

In addition to scores on routine outcome measures we examined clinical outcomes for each young person. Following completion of Brief BA, 13 young people (65\%) required no further psychological input; of this group eight were discharged from the service completely and five remained on SSRI medication (so required on-going psychiatric monitoring). Of the remaining seven young people, four were referred for CBT (three for anxiety, one for anxiety and low mood). Two young people were offered additional input in CAMHs but declined this (one who had disengaged with Brief BA, and one who was offered both group CBT for anxiety and family therapy). One young person was referred to adult mental health services for CBT for anxiety as she was almost 18.

\section{Reliable and Clinically Significant Change: RCADS Depression subscale}

Reliable change on the RCADS depression subscale was indicated by a change score greater than the published Reliable Change Criterion (RCC) based on each individual's age and gender. Clinically significant change was defined as moving down a clinical category. Two young people were already in the normal range on the RCADS Depression subscale at assessment, therefore clinically significant change was not possible. Out of the remaining 18, six $(33 \%)$ showed reliable and clinically significant change between assessment and session 8. Two showed reliable improvement but did not change clinical category, while the others did not show reliable change in their scores. Between assessment and BA review session, seven (39\%) of the 18 young people who could evidence reliable and clinically significant change showed this. Three others also showed reliable improvement but did not change clinical category.

\section{Reliable and Clinically Significant Change: ORS}

Four young people scored in the normal range (28+) on the ORS at assessment so clinically significant change was not possible. Six (38\%) of the 16 young people able to 
evidence reliable and clinically significant change (increase of more than 5 points and move from clinical to normal range) showed this between assessment at BA session 8. Another four showed reliable improvement but their ORS scores remained in the clinical range.

Between assessment and BA review, eight (50\%) of the 16 young people who could show reliable and clinically significant change evidenced this. Another young person showed reliable improvement but remained in the clinical range.

\section{Treatment Satisfaction}

Therapeutic alliance ratings were high across all Brief BA sessions, with mean SRS scores ranging from 35.55 (session 1) to 38.09 (session 7). At the end of treatment, feedback was received from 17 young people and 16 parents. The majority (over 70\%) reported that they liked or really liked Brief BA, and importantly, nobody said they disliked it. Nearly all (94\%) of young people reported they would definitely or probably recommend Brief BA to a friend, and $88 \%$ found the approach useful. Open ended comments were also positive, including on the therapeutic relationship (e.g. 'they truly listened to me', 'being able to talk freely') and often directly about the Brief BA content (e.g. 'It made me think about my activities and how they affect my mood', 'I like that it made me think about my own values').

Over $75 \%$ of parents liked or really liked Brief BA, $81 \%$ found it very or fairly useful, and over $87 \%$ would recommend the treatment to a friend for their child. Positive parental comments identified the practical elements of Brief BA (e.g. 'the focus on positive outcomes and encouraging activities, and a balance of fun and social as well as achievement') and the importance of the therapeutic relationship (e.g. 'the therapist treated [young person] like a young adult').

When asked what they liked least about Brief BA, four young people chose not to write anything and one young person stated 'nothing, I liked it all'. The others identifiedvarious minor issues, including challenges with completing activity logs and engaging in the work between sessions (e.g. 'the activity logs at the start', 'having to organise things'). Five parents did not identify any negative aspect of Brief BA. A few identified concerns over the brief nature of the intervention (e.g. ' 8 weeks was probably too short, I feel she needs a little more help'), or practical issues (e.g. 'planning appointments'). Two parents commented that they should have had greater involvement in the treatment (e.g. 'I sometimes felt that my concerns about my child were not considered', 'the lack of communication between therapist, child and parent- a debrief I felt was needed to end the session'). 


\section{Discussion}

The aim of this pilot study was to investigate the acceptability, feasibility and clinical effectiveness of a brief, structured behavioural intervention adapted for adolescents within a routine CAMHs setting. The high treatment completion rate, SRS ratings and feedback scores suggest Brief BA was acceptable to both young people and their parents. Brief BA resulted in a significant decrease in depression symptoms over the course of treatment and a significant increase in functioning on both self and parent report. The treatment effect size on depression symptoms was large, and the majority of young people (65\%) needed no further psychological intervention following Brief BA. These findings are promising (particularly given this was a routine CAMHs population with a range of co-morbidity, suicidal ideation and previous therapy experience), and suggest that Brief BA warrants further evaluation on a larger scale.

Developing alternative treatments for adolescent depression is important and urgent. Adolescent depression is a serious health problem, a cause of great distress and long-term impairments in functioning and a leading cause of premature death (Thapar, Collishaw, Pine, \& Thapar, 2012). A number of evidence-based psychological therapies are recommended but they have some serous limitations. First, and perhaps most importantly, many young people do not engage with treatment and drop out before they receive the planned number of sessions. Secondly, existing psychological treatments (e.g. CBT, IPT, family therapy) are complex, require lengthy training and are delivered by specialist psychological therapists. This means that access to treatment is extremely limited and most young people with depression (or other mental health problems) are not able to access treatment at all or must endure lengthy waiting lists. Evidence-based treatments therefore are simply not able to meet the needs of the majority of depressed young people.

Brief Behavioural Activation has the potential to overcome these two key limitations of existing therapies, engagement and accessibility. Brief BA treatment appears to engage young people successfully in treatment - although this must be examined in a larger sample and in other clinical settings. Features of Brief BA that may appeal more to young people include it being short-term, focused and simple to understand. Brief BA builds on a strong theoretical base (learning theory) that can explain symptoms of depression in simple (as well as more complex) terms. This simple version of the model can be adapted to the individual young person and their experience, and leads directly to a treatment plan. Successful engagement in any treatment is extremely important because it means that depressed young people are more likely to receive a full 'dose' of treatment and end therapy through mutual 
agreement with their therapist. If further treatment (medication or a more intensive psychological therapy) is then required, this engagement means that care can be more continuous and coherent and the well-being of the young person can be monitored.

BA also has the potential to be more accessible to young people. This is because the simple model of depression and treatment plan can be delivered to patients in a flexible but highly structured format. The treatment has been designed so that it could be delivered skilfully, and with fidelity, by professionals who are not fully trained psychotherapists. If effective interventions can be delivered by a wider range of professionals, in community settings (e.g. schools) there is potential to provide this brief focused and simple therapy to young people more promptly and efficiently.

However, this pilot study can only provide data that supports further research and evaluation of Brief BA. The treatment was provided in just one clinical setting by members of a team responsible for adapting Brief BA for depressed adolescents. The intervention clearly needs to be evaluated in more independent clinical settings to assess if these promising data can be replicated in services not directly affiliated with the research team, and in different types of services and staff teamsIn addition, the absence of a control or active comparison treatment group means we cannot compare outcomes of Brief BA with current evidence-based treatments. Recent reviews (Weisz et al., 2006) and treatment trials (Goodyer et al., 2017) suggest that a range of psychological therapies for depression are equivalent. It is possible that Brief BA is not more effective than other psychological therapies; however, it may be more cost effective, and even more importantly, more acceptable to young people who are depressed.

These are promising preliminary results that need to be investigated further. However, Brief BA could be one possible solution to considerably stretched CAMH services delivering effective, cost effective, and engaging therapies to adolescents with depression. 
Acknowledgements: We would like to thank Gemma Brisco, Lizzie Hodgson for their help delivering Brief BA, and Hannah Whitney for clinical supervision. We would also like to thank the local NHS trust for allowing dissemination of these findings, and to all the young people and families who took part.

Ethical statement: The authors assert that all procedures contributing to this work comply with the ethical standards of the relevant national and institutional committees on human experimentation and with the Helsinki Declaration of 1975, and its most recent revision.

Conflicts of interest: The authors have no conflict of interest with respect to this publication.

Financial support: This research received no specific grant from any funding agency, commercial or not-for-profit sectors.

\section{References}

American Psychiatric Association. (1994). Diagnostic and statistical manual of mental disorders: DSM-IV. (4th ed). Washington, DC: American Psychiatric Association.

Cash, S. J., \& Bridge, J. A. (2009). Epidemiology of youth suicide and suicidal behavior. Current opinion in pediatrics, 21, 613-619. doi: 10.1097/MOP.0b013e32833063e1.

Chorpita, B. F., Yim, L., Moffitt, C., Umemoto, L. A., \& Francis, S. E. (2000). Assessment of symptoms of DSM-IV anxiety and depression in children: A revised child anxiety and depression scale. Behaviour Research and Therapy, 38, 835-855. doi: $\underline{10.1016 / \mathrm{S} 0005-7967(99) 00130-8 .}$

Chorpita, B. F., Moffitt, C. E., Gray, J. A. (2005). Psychometric properties of the revised child anxiety and depression scale in a clinical sample. Behaviour Research and Therapy, 43, 309-322. doi: 10.1016/j.brat.2004.02.004.

Cohen, J. (1992). A power primer. Psychological Bulletin, 112, 155-159.

Cuijpers, P., van Straten, A., Andersson, G., \& van Oppen, P. (2008). Psychotherapy for depression in adults: a meta-analysis of comparative outcome studies. Journal of consulting and clinical psychology, 76(6), 909. 
Duncan, B. L., Miller, S. D., Sparks, J. A., Claud, D. A., Reynolds, L. R., Brown, J., \& Johnson, L. D. (2003). The Session Rating Scale: Preliminary psychometric properties of a "working" alliance measure. Journal of brief Therapy, 3, 3-12.

Duncan B. L., Sparks J., Miller S. D., Bohanske R., \& Claud D. (2006). Giving youth a voice: A preliminary study of the reliability and validity of a brief outcome measure for children, adolescents, and caretakers. Journal of Brief Therapy, 5, 66-82.

Ebesutani, C., Bernstein, A., Nakamura, B. J., Chorpita, B. F., \& Weisz, J. R. (2010). A psychometric analysis of the revised child anxiety and depression scale-parent version in a clinical sample. Journal of Abnormal Child Psychology, 38(2), 249-260. doi: 10.1007/s10802-009-9363-8.

Ekers, D., Richards, D., \& Gilbody, S. (2008). A meta-analysis of randomized trials of behavioural treatment of depression. Psychological medicine, 38(5), 611-623. doi: 10.1017/S0033291707001614.

Ekers, D., Webster, L., Van Straten, A., Cuijpers, P., Richards, D., \& Gilbody, S. (2014). Behavioural activation for depression; an update of meta-analysis of effectiveness and sub group analysis. Plos One, 9(6), e100100. doi: 10.1371/journal.pone.0100100.

Fletcher, J. M. (2008). Adolescent depression: diagnosis, treatment, and educational attainment. Health economics, 17, 1215-1235. doi: 10.1002/hec.1319.

Goodyer, I. M., Reynolds, S., Barrett, B., Byford, S., Dubicka, B., Hill, J., ... \& Fonagy, P. (2016). Cognitive behavioural therapy and short-term psychoanalytical psychotherapy versus a brief psychosocial intervention in adolescents with unipolar major depressive disorder (IMPACT): a multicentre, pragmatic, observer-blind, randomised controlled superiority trial. The Lancet Psychiatry. doi:10.1016/S22150366(16)30378-9.

House of Commons Health Committee (2014). Children's and adolescents' mental health and CAMHS. Third report of session 2014-2015. London: The Stationary Office Limited. Retrieved from: http://www.publications.parliament.uk/pa/cm201415/cmselect/cmhealth/342/34202.ht $\mathrm{m}$

Lejuez, C. W., Hopko, D. R., \& Hopko, S. D. (2001). A brief behavioral activation treatment for depression: Treatment manual. Behavior Modification, 25, 255-286. doi: 10.1177/0145445501252005. 
Lejuez, C. W., Hopko, D. R., Acierno, R., Daughters, S. B., \& Pagoto, S. L. (2011). Ten year revision of the brief behavioral activation treatment for depression : Revised treatment manual. Behavior Modification, 35, 111-161. doi: 10.1177/0145445510390929.

Martell, C. R., Addis, M. E., \& Jacobson, N. S. (2001). Depression in context: Strategies for guided action. New York: Norton.

Martell, C. R., Dimidjian, S., \& Hermann-Dunn, R. (2010). Behavioral activation for depression: A clinician's guide. New York: Guilford.

McCauley, E., Gudmundsen, G., Schloredt, K., Martell, C., Rhew, I., Hubley, S., \& Dimidjian, S. (2015). The adolescent behavioral activation program: Adapting behavioral activation as a treatment for depression in adolescence. Journal of Clinical Child \& Adolescent Psychology, 1-14. doi: 10.1080/15374416.2014.979933.

McLeod, G. F. H., Horwood, L. J., \& Fergusson, D. M. (2016). Adolescent depression, adult mental health and psychosocial outcomes at 30 and 35 years. Psychological medicine, 46, 1401. doi: 10.1017/S0033291715002950.

Miller, S. D., \& Duncan, B. L. (2000) The outcome rating scale. Chicago: Author.

National Institute for Health and Care Excellence (2015). CG28 Depression in children and young people: Identification and management in primary, community and secondary care. NICE clinical guideline 28, September 2005. Updated March 2015. Retrieved from http://www.nice.org.uk/guidance/cg28

National Institute for Health and Care Excellence (2016). CG90 Depression in adults: Recognition and management. NICE clinical guideline 90, October 2009. Updated April 2016. Retrieved from http://www.nice.org.uk/guidance/cg90

National Society for the Prevention of Cruelty to Children (2015). Postcode lottery of waiting times in local mental health services. Retrieved from: https://www.nspcc.org.uk/fighting-for-childhood/news-opinion/postcode-lottery-ofwaiting-times-in-local-mental-health-services/

Orchard, F., Pass, L., Marshall, T. \& Reynolds, S. (2016). Clinical characteristics of adolescents referred for treatment of depressive disorders. Child and Adolescent Mental Health. doi: 10.1111/camh.12178.

Pass, L., Brisco, G., Hodgson, E., \& Reynolds, S. (2015). Brief Behavioural Activation for depressed adolescents (Brief BA) Therapist guide. Unpublished manual, University of Reading.

Pass, L., \& Reynolds, S. (2014). Treatment manual for Brief Behavioural Activation for depressed adolescents (Brief BA). Unpublished manual, University of Reading. 
Pass, L., Brisco, G., \& Reynolds, S. (2015). Adapting brief Behavioural Activation (BA) for adolescent depression: A case example. The Cognitive Behaviour Therapist, 8, e17. doi: $10.1017 /$ S1754470X15000446

Pass, L., Whitney, H., \& Reynolds, S. (2016). Brief Behavioural Activation (BA) for adolescent depression: Working with complexity and risk. doi: $10.1177 / 1534650116645402$.

Pass, L., Hodgson, E., Whitney, H., \& Reynolds, S. (in press). Brief Behavioural Activation treatment for depressed adolescents (Brief BA) by non-specialist clinicians: A case illustration. Child and Adolescent Mental Health.

Polanczyk, G. V., Salum, G. A., Sugaya, L. S., Caye, A., \& Rohde, L. A. (2015). Annual research review: A meta-analysis of the worldwide prevalence of mental disorders in children and adolescents. Journal of Child Psychology and Psychiatry, 56, 345-365. doi: 10.1111/jcpp.12381.

Richards, D. A., Ekers, D., McMillan, D., Taylor, R. S., Byford, S., Warren, F. C., ... Finning, K. (2016). Cost and Outcome of Behavioural Activation versus Cognitive Behavioural Therapy for Depression (COBRA): a randomised, controlled, noninferiority trial. The Lancet. Advance online publication. doi:10.1016/S0140$\underline{6736(16) 31140-0}$

Ruggiero, K. J., Morris, T. L., Hopko, D. R., \& Lejuez, C. W. (2005). Application of Behavioral Activation Treatment for Depression to an adolescent with a history of child maltreatment. Clinical Case Studies, 2, 1-17. doi: 10.1177/1534650105275986.

Stem4 (2016). “A Time Bomb Waiting to Explode” A Survey of GPs' Concerns about Mental Health Services for Children and Young People [online report]. Retrieved from http://www.stem4.org.uk/wp-content/uploads/2016/11/A-Time-Bomb-Waitingto-Explode.pdf

Thapar, A., Collishaw, S., Pine, D. S., \& Thapar, A. K. (2012). Depression in adolescence. The Lancet, 379, 1056-1067.

Weisz, J. R., McCarty, C. A., \& Valeri, S. M. (2006). Effects of psychotherapy for depression in children and adolescents: a meta-analysis. Psychological Bulletin, 132, 132-149. doi: 10.1037/0033-2909.132.1.132. 